\title{
Studi Analisis Perilaku Sambungan Kaku (Rigid Connection) Balok - Kolom Baja Tipe Extended End Plate dengan Metode Elemen Hingga
}

\author{
Oktavia Ully Artha Silalahi ${ }^{1, *}$, Budi Suswanto ${ }^{1}$, Bambang Piscesa ${ }^{1}$ \\ Departemen Teknik Sipil, Institut Teknologi Sepuluh Nopember, Surabaya ${ }^{1}$ \\ Koresponden*,Email: okta.omk@gmail.com
}

\begin{tabular}{lrl}
\hline \multicolumn{1}{c}{ Info Artikel } & Abstract \\
\hline $\begin{array}{l}\text { Diajukan } \\
\text { Diperbaiki }\end{array}$ & 9 Juli 2019 & $\begin{array}{l}\text { Post-earthquake building failure or collapse is determined by the quality of the connection. } \\
\text { Disetujui }\end{array}$ \\
& 2 Agustus 2019 & $\begin{array}{l}\text { The selection of the right connection is very necessary to ensure the occurrence of plastic joints } \\
\text { in the beam area. This study discusses the behavior of Extended End Plate type steel } \\
\text { connections when given cyclic loads using software based on ABAQUS } 6.14 . \text { This study will do } \\
\text { modeling which then results will be compared from moment }- \text { rotation, rotational stiffness } \\
\text { value and failure mode using software based on ABAQUS } 6.14 . \text { The modeling used I-Shaped } \\
\text { welded plate for column dimensions } 300 \times 250 \times 8 \times 12 \text { mm and beam dimensions } 300 \times 200 \times 8 \times 12 \\
\text { mm, column stiffness thickness } 12 \text { mm, thickness of } 10 \text { mm extended end plate stiffener. The } \\
\text { results of the modeling above when compared with the results of the experiments used do not } \\
\text { have a significant difference. The modeling results with the auxiliary program finite element } \\
\text { is an approach so that the results are not exactly the same as the results of the experiments } \\
\text { conducted. Based on the results of the modeling performed, modeling on the joint has good } \\
\text { ductility. }\end{array}$
\end{tabular}

\section{Abstrak}

Kegagalan atau keruntuhan bangunan pasca gempa ditentukan oleh kualitas sambungan. Pemilihan sambungan yang tepat sangat diperlukan untuk menjamin terjadinya sendi plastis pada daerah balok. Studi ini membahas tentang perilaku dari sambungan baja tipe Extended End Plate saat diberi beban siklik dengan menggunakan software ABAQUS 6.14. Hasil eksperimental berupa momen-rotasi, nilai kekakuan rotasi dan adanya mode kegagalan akan dibandingkan dengan pemodelan yang dilakukan pada program ABAQUS 6.14. Pemodelan yang digunakan welded plate I-Shaped dengan dimensi kolom

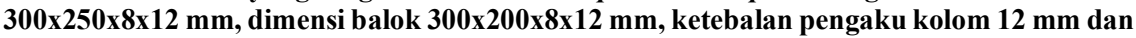
ketebalan pengaku extended end plate $10 \mathrm{~mm}$. Hasil pemodelan yang sudah didapat jika dibandingkan dengan hasil eksperimental tidak memiliki selisih yang signifikan. Hasil pemodelan dengan program bantu finite element merupakan sebuah pendekatan sehingga hasilnya tidak sama persis dengan hasil eksperimen yang dilakukan. Berdasarkan hasil pemodelan yang dilakukan pemodelan pada sambungan memiliki kemampuan daktilitas

Kata kunci: Pembebanan siklik, plat ujung tambahan, metode elemen hingga, sambungan baja yang baik.

\section{Pendahuluan}

Indonesia merupakan Negara dengan aktivitas kegempaan yang sangat tinggi. Menurut United States Geological Survey - National Earthquake Information Center (USGS - NEIC), tercatat untuk wilayah Kepulauan Indonesia dalam rentang waktu antara tahun $1973-2009$ terjadi 8.260 kejadian gempa dengan magnituda $\mathrm{M}>5,0 \mathrm{SR}$ sesuai penelitian Lina[1]. Salah satu dampak yang diakibatkan oleh gempa tersebut yaitu merusak infrastruktur salah satunya bangunan gedung. Oleh karena itu, regulasi perencanaan bangunan terkait dengan aktivitas kegempaan di Indonesia sudah mulai digunakan sejak tahun 1983 dan telah diperbaharui pada tahun 2002 dan 2012. Mengingat lokasi kejadian yang tidak bisa diperkirakan secara akurat dan kebutuhan wilayah yang mendesak, usaha untuk mengurangi dampak gempa dilakukan dengan perencanaan dan pembangunan gedung yang tahan terhadap gempa.

Salah satu kerusakan yang sering terjadi pada gedung bertingkat akibat gempa adalah pada sambungan balok - kolom pada struktur baja. Studi yang dilakukan menunjukkan bahwa kegagalan getas yang terjadi pada sambungan lebih besar daripada probabilitas kegagalan yang direncanakan sebelumnya sesuai eksperimentail Vahid et al.[2]. Kegagalan desain sambungan serta besarnya ketidakcocokan antara perilaku yang dianalisis dan perilaku aktual, akan membuat sambungan memiliki keterbatasan kemampuan dalam menerima beban oleh eksperimental Biliana [3]. Sambungan baut end-plate sebagai salah satu sambungan yang mampu menahan momen besar akibat beban yang terjadi. 
Penggunaan sambungan tersebut juga sudah secara meluas digunakan pada gedung bertingkat struktur baja.

Pada studi analisis ini, tipe sambungan yang akan dianalisis perilakunya adalah sambungan balok - kolom baja dengan menggunakan tipe extended end plate sesuai penelitian Mehdi et al. [2]. Sambungan extended end plate adalah salah satu tipe sambungan dari jenis sambungan semirigid. Sambungan semirigid memiliki kekakuan mendekati sambungan rigid akan tetapi mempunyai fleksibilitas seperti halnya pada simple connection sesuai AISC [4]. Penggunaan sambungan tipe extended end plate menjadi populer akhir-akhir ini. Selain memiliki performa yang baik dalam menahan beban yang terjadi, tipe ini juga dalam pelaksanaannya di lapangan memiliki kemudahan dalam hal fabrikasi dan ereksi sesuai Abbas et al. [5]. Selain itu, sambungan tipe extended end plate perlu ditinjau perilakunya dengan memberikan beban siklik untuk mengetahui batas inelastik pada keseluruhan sambungan sesuai dengan parameter yang digunakan oleh Ghobarah et al. [6]. Selain tes secara eksperimental yang dapat dilakukan pada sambungan, test secara analisis non-linier dengan metode elemen hingga yang berbaris komputer juga menjadi alternatif yang sudah banyak digunakan untuk meninjau perilaku sambungan. Penggunaan dengan metode elemen hingga non-linier dapat memperluas interpretasi untuk membandingkan hasil dan observasi penelitian eksperimen yang telah dilakukan sebelumnya oleh Mohammed et al. [7].

\section{Tinjauan Pustaka}

Suatu struktur dapat tersusun dari beberapa elemen, dengan sifat atau karakteristik yang berlainan. Berdasarkan elemen-elemen penyusunnya, struktur dapat dibedakan menjadi 4 macam yaitu Struktur Balok - Kolom, Struktur Trusses (Struktur Rangka Batang), Struktur Frame (Struktur Rangka Kaku), dan Struktur Shell (meliputi plate, Shell dan Membran). Adapun tipe model sambungan berdasarkan sifat kekakuannya (rigidity), metode perencanaan rangka dapat diklasifikasikan meliputi, simple connection, rigid dan semirigid seperti pada Tabel 1.

Pada umumnya, kurva momen - rotasi dari sebuah sambungan dapat memberikan beberapa sifat atau karakteristik sebagai berikut:

1. Kekakuan dari sebuah sambungan diidentifikasi dari kemiringan kurva.

2. Perilaku sambungan pada umumnya adalah non-linier, dimana kekakuan menurun sedangkan rotasi meningkat.

3. Secara teori, kekakuan awal mempunyai angka yang sama dengan kekakuan setelah dibebani.
4. Kekakuan dari titik kumpul adalah indikasi dari nilai momen kapasitas yang dapat diambil dari nilai tertinggi pada kurva momen - rotasi.

5. Pada Gambar 1, daktilitas meningkat seiring meningkatnya rotasi.

Daktilitas dari sambungan adalah indikasi dari kapasitas rotasi yang didapat dari titik kumpul sebelum terjadi kehilangan kekuatan secara signifikan. Sebuah sambungan dapat dinyatakan ductile (elastis) jika memenuhi syarat bahwa rotasi yang terjadi lebih besar dari 0.03 radians sesuai analisis Valerio et al. [8].

Tabel 1. Tipe Model Sambungan

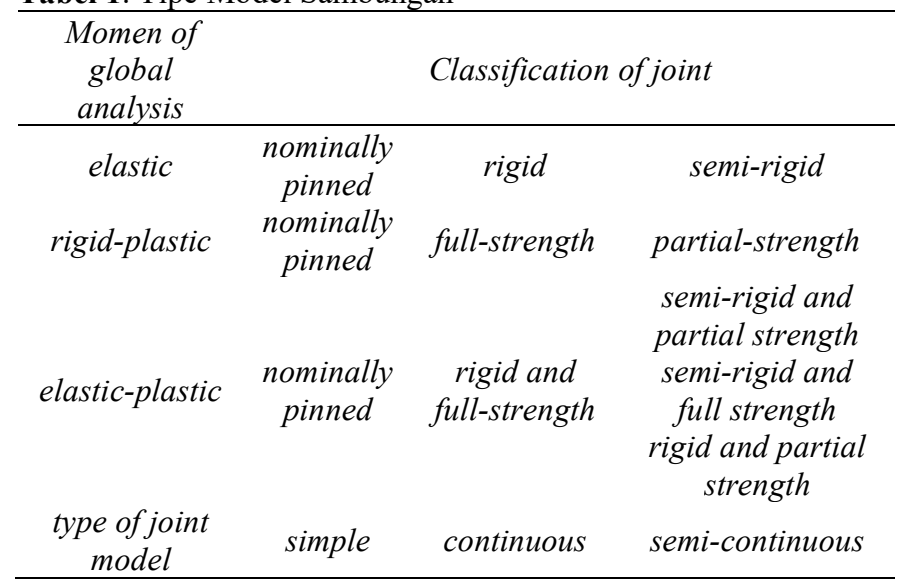

Sumber: Valerio et al., 2012

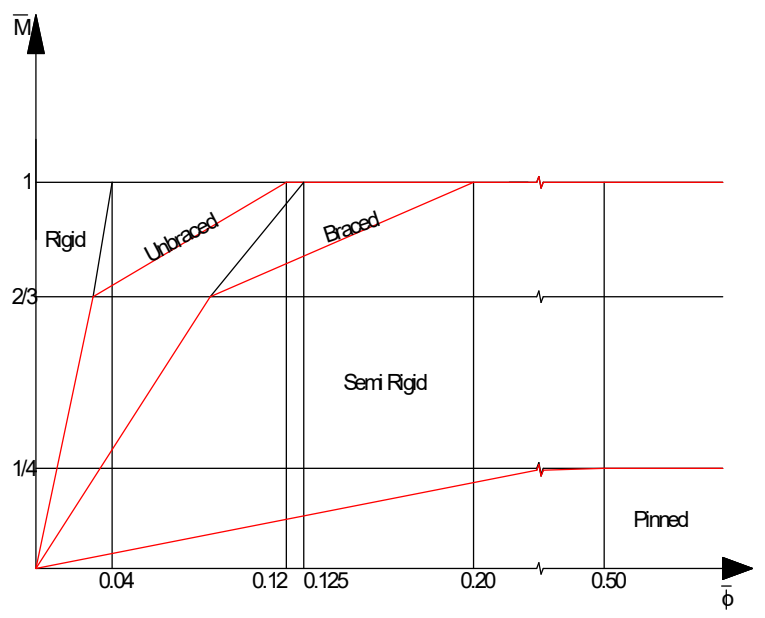

Gambar 1. Kurva Momen - Rotasi (M - Ø)

Sumber: Valerio et al., 2012

Sambungan momen untuk tipe end-plate dibagi menjadi tiga bentuk: flush end plate connections, extended end plate 
connections dan welded connections dikategorikan oleh Anton Soekiman dkk.

\section{Metode}

Metode penelitian dimulai dengan persiapan data dari eksperimen sebelumnya mengenai kolom dan balok baja dengan menggunakan sambungan baut mutu tinggi. Data properti dan geometri dari kolom baja, balok baja, baut mutu tinggi, end-plate dan stiffener yang diambil dalam penelitian ini adalah data penelitian eksperimental yang dilakukan Gang Shi et al.[9] mengenai perilaku dari sambungan momen end-plate di bawah pembebanan siklik. Pemodelan kolom baja, balok baja, baut mutu tinggi, end-plate dan stiffener sesuai dengan data geometri. Pendefinisian perilaku material baja dan baut mutu tinggi didapatkan dari data properti yang didekati dengan persamaan empiris dengan input nilai density, elastic dan plastic dari baja dan baut mutu tinggi yang digunakan. Persamaan empiris tersebut meliputi persamaan tegangan-regangan baja dan tegangan-regangan baut mutu tinggi. Dari hubungan tegangan - regangan tesebut didapat regangan inelastik kemudian dihitung menjadi hubungan momen-rotasi yang nilai dari perubahan sudut yang berpengaruh pada nilai rotasi dan jarak ujung balok ke badan kolom akan dikalikan dengan gaya yang didapat pada perilaku sambungan baja. Input hasil studi parameter tegangan-regangan baja dan baut mutu tinggi menjadi acuan dalam input pemodelan kolom dan balok baja serta baut mutu tinggi. Kemudian hasil running pemodelan kolom baja, balok baja dan baut mutu tinggi berupa kurva moment rotasi akan diverifikasikan dengan kurva hasil eksperimen dari Gang Shi et al[9].

\section{Material Properties}

Hasil eksperimental dari Gang Shi et al.[9] ini menjadi acuan dalam pemodelan. Hasil eksperimen ini dianggap sebagai perilaku yang sebenarnya terjadi pada jenis sambungan akibat beban siklik. Parameter - parameter yang diinput ke definisi perilaku material khusunya material steel dan bolts pada ABAQUS dapat disajikan pada Tabel 2. Parameter-parameter tersebut diinputkan ke dalam perilaku sambungan pada baja. Spesifikasi dan ukuran sambungan dapat dilihat pada Tabel 3. mengenai parameter sambungan. Nantinya hasil eksperimen ini sangat berguna untuk memverifikasi atau mengoreksi hasil dari pemodelan yang dilakukan agar hasil pemodelan dapat dikontrol terhadap hasil eksperimen yang sudah ada. Adapun material pada komponen didefinisikan pada modul property pada program ABAQUS. Sifat dan karakteristik tiap material dimasukkan datanya ke dalam modul properti ini. Pada pemodelan yang akan dianalisis perilakunya maka material baja dan baut mutu tinggi antara lain density, elastic, dan plastic nilainya diinputkan ke program ABAQUS. Perilaku elastis pada steel dan high tension bolt (HTB) didefinisikan oleh nilai modulus elastis dan poisson ratio sebesar 0,3.

Tabel 2. Material Properties dan Spesimen Model

\begin{tabular}{cccc}
\hline Material & $f y$ & $f u$ & $\begin{array}{c}\text { Modulus } \\
\text { Elastisitas } \\
(E)\end{array}$ \\
& & & $(\mathrm{MPa})$ \\
\hline Steel $(\mathrm{t}<16 \mathrm{~mm})$ & 391 & 559 & 190707 \\
Steel $(\mathrm{t}>16 \mathrm{~mm})$ & 363 & 573 & 204228 \\
Bolts (M20) & 995 & 1160 & 204228 \\
\hline
\end{tabular}

Tabel 3. Parameter Sambungan

\begin{tabular}{lc}
\multicolumn{1}{c}{ Tipe Sambungan } & Extended \\
\hline Dimensi Kolom & $300 \times 250 \times 8 \times 12$ \\
Dimensi Balok & $300 \times 200 \times 8 \times 12$ \\
Tebal End Plate $(\mathrm{mm})$ & 20 \\
Tebal Column Stiffener $(\mathrm{mm})$ & 12 \\
Tebal Extended End Plate Stiffener & 10 \\
$(\mathrm{~mm})$ & \\
Mutu Baja & $\mathrm{Q} 345$ \\
Mutu Baut & Grade 10.9 \\
Diameter Baut $(\mathrm{mm})$ & $\mathrm{M} 20$ \\
Las & E70XX \\
Pretension Bolt & Ya \\
\hline
\end{tabular}

\section{Kontrol Penampang dan Sambungan}

\section{a. Kuat Rencana}

Desain komponen struktur untuk mendapatkan kuat rencana dikontrol berdasarkan SNI 1729:2015 [10] agar dapat memikul gaya-gaya yang terjadi. Perencanaan komponen struktur dilakukan untuk mengetahui besar tegangan kritis dan faktor ketahanan pada sambungan yang ditinjau dari kekuatan tarik, tekan, lentur dan geser yang terjadi.

Adapun rumus untuk komponen struktur tanpa elemen langsing adalah sebagai berikut :

Tekuk Lentur : $\emptyset c=0,90$

Tegangan kritis, $F_{c r}$ yang ditentukan adalah :

$$
\begin{gathered}
\text { Bila } \frac{\mathrm{KL}}{\mathrm{r}} \leq 4,71 \sqrt{\mathrm{E} / \mathrm{Fy}} \quad\left(\text { atau } \frac{F y}{F e} \leq 2,25\right) \\
F_{c r}=\left[0,658^{F y / F e}\right] F_{y} \\
\text { Bila } \frac{\mathrm{KL}}{\mathrm{r}} \leq 4,71 \sqrt{\mathrm{E} / \mathrm{Fy}} \quad\left(\text { atau } \frac{F y}{F e}>2,25\right) \\
F_{c r}=0,877 F_{e} \\
F_{e}=\frac{\pi^{2} E}{\left(\frac{K L}{r}\right)^{2}}
\end{gathered}
$$


Adapun rumus untuk komponen struktur dengan elemen langsing adalah sebagai berikut :

$$
\begin{gathered}
\text { Bila } \frac{\mathrm{KL}}{\mathrm{r}} \leq 4,71 \sqrt{\mathrm{E} / \mathrm{QFy}} \quad\left(\text { atau } \frac{Q F y}{F e} \leq 2,25\right) \\
F_{c r}=\mathrm{Q}\left[0,658^{Q F y / F e}\right] F_{y}
\end{gathered}
$$

\section{b. Kontrol Sambungan}

Berdasarkan SNI 1729:2015 [10] tentang Cara Perencanaan Struktur Baja untuk Bangunan Gedung, maka perbandingan momen kolom terhadap momen balok harus dihitung. Hubungan berikut ini harus dipenuhi pada sambungan balok - kolom. Adapun rumus konsep Strong Column Weak Beam adalah sbb:

$$
\begin{aligned}
& \frac{\Sigma M_{p c}}{\Sigma M_{p b}}>1 \\
& \Sigma \mathrm{M}^{*}{ }_{\mathrm{pc}}=2 \times\left(\mathrm{Zcx}\left(f y-\frac{N u c}{A g}\right)\right) \\
& \Sigma \mathrm{M}_{\mathrm{pb}}^{*}=1.1 \times \mathrm{R}_{\mathrm{y}} \times \mathrm{f}_{\mathrm{y}} \times \mathrm{Z}_{\mathrm{X}}+\mathrm{M}_{\mathrm{y}}
\end{aligned}
$$

\section{c. Kontrol Panel Zone}

Bila $\mathrm{Nu} \leq 0,75 \mathrm{~N}_{\mathrm{y}}, \emptyset_{\mathrm{v}} \mathrm{V}_{\mathrm{n}}=0,6 \mathrm{x} \emptyset_{\mathrm{v}} \mathrm{xf}_{\mathrm{y}} \mathrm{xd}_{\mathrm{c}} \mathrm{xt}_{\mathrm{p}}$

$$
\left[1+\frac{3 b_{c f} x t_{c f}^{2}}{d_{b} d_{c} t_{p}}\right]
$$

Berdasarkan Tata Cara Perencanaan Struktur Baja untuk Bangunan Gedung Pasal 15.7.3.2, tebal daerah panel adalah ketebalan masing-masing pelat badan penampang kolom atau pelat pengganda pada daerah panel, ditetapkan menurut persamaan berikut :

$$
\mathrm{t} \geq\left(\mathrm{d}_{\mathrm{z}}+\mathrm{w}_{\mathrm{z}}\right) / 90
$$

\section{Studi Parameter Sambungan}

Pada penelitian ini, terdapat dua tipe sambungan dari eksperimental yang akan dianalisis dan untuk lanjutan pemodelan menggunakan tipe sambungan yang sama dengan memvariasikan gaya pratarik pada baut mutu tinggi yang akan digunakan. Studi input parameter pada sambungan steel dan bolts kemudian dimodelkan dan dianalisis juga hubungan antara kuat tarik dan pertambahan panjang yang terjadi akibat pengaruh gaya pratarik baut. Setelah didapat hasil dari studi yang dimodelkan akan dilakukan verifikasi hasil hubungan gaya dan displacement akibat beban monotonik dan siklik. Hubungan gaya dan displacement akan dikonversikan menjadi hubungan momen-rotasi yang didapat dari metode elemen hingga (ABAQUS) yang kemudian dibandingkan terhadap hasil pendekatan Gang Shi et al. [9].

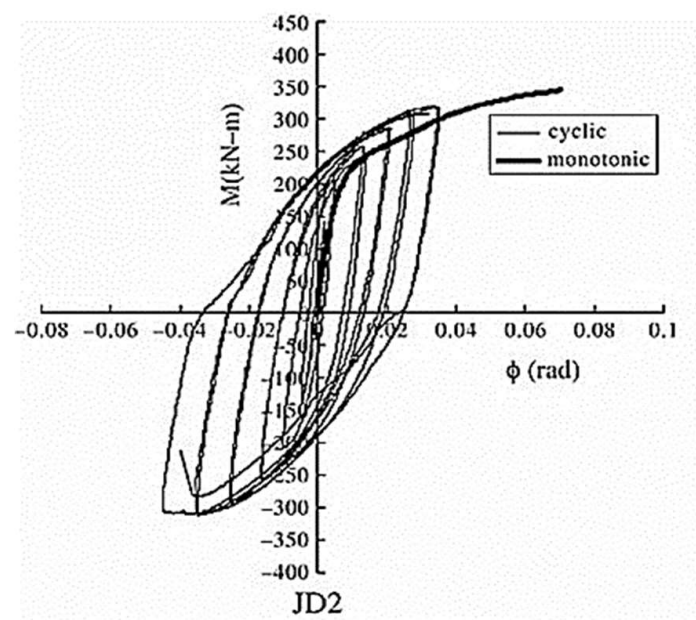

Gambar 2. Kurva Momen - Rotasi dari Spesimen JD2

Gambar 2 dan Gambar 3 menunjukkan hasil kurva histerisis dari spesimen eksperimental yang akan dibandingkan dengan hasil numerik yang dilakukan pada program ABAQUS. Kurva momen-rotasi tersebut adalah kontribusi geser yang terjadi pada panel zone di kolom yang mengakibatkan terjadinya rotasi gap yang menimbulkan deformasi relatif antara end-plate dan sayap kolom. Untuk menganalisis specimen JD2 dan JD4 pada program ABAQUS, maka parameter dan ketentuan material mengacu pada parameter pada eskperimental yang digunakan. Pada sambungan akan dianlisis mengunakan baut mutu tinggi akan ada kontak permukaan antara end-plate dan sayap kolom yang kemudian akan muncul mekanisme slip yang nilai koefisien sebesar 0,44.

Setelah diverifikasi hasil metode finite element menggunakan program ABAQUS dengan hasil eksperimen, maka pemodelan lanjutan akan dilakukan dengan meninjau gaya pratarik baut dengan variasi persen pratarik baut. Pemodelan yang sudah dianalisis sebelumnya, untuk besar kekuatan tarik minimum baut mengacu pada SNI 1729:2015 [10] mengenai besar nilai pratarik awal yang digunakan pada baut yaitu sebesar $70 \%$ dari kekuatan tarik minimum baut yang digunakan.

\section{Detail Spesimen}

Spesimen yang akan dimodelkan terdiri dari dua spesimen, yaitu spesimen tipe JD2 dan tipe JD4 yang diambil dari data penelitian eksperimental oleh Gang Shi et al.[9]. 


\section{Pemodelan Numerik}

Pemodelan yang digunakan pada ABAQUS dengan solid-extrusion. Pemodelan menggunakan welded plaie I Shaped. Pemodelan balok-kolom baja, end-plate, column stiffener, extended stiffener dan bolts dimodelkan awal pada bagian modul part. Adapun contoh modul part yang dimodelkan pada ABAQUS dapat dapat dilihat yaitu kolom baja pada Gambar 6. Pada elemen yang dirangkai pada bagian part akan menggunakan type deformable dengan menggunakan create lines connected. Kemudian akan dilanjutkan dengan masuk ke tahap pemberian material pada modul property. Part yang telah dibuat, digabungkan menjadi satu kesatuan pemodelan. Untuk pemodelan las digunakan jenis interaction berupa tie constraint.

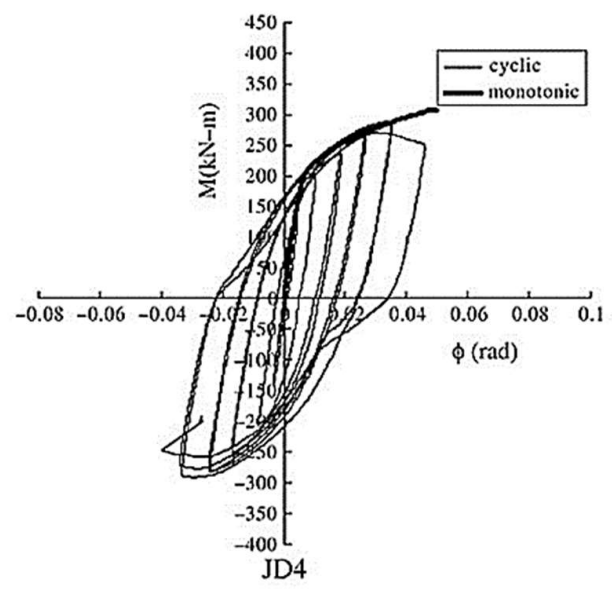

Gambar 3. Kurva Momen - Rotasi dari Spesimen JD4

Tabel 4. Rekapitulasi dari Variasi \% Pratarik Baut

\begin{tabular}{cc}
\hline Nama Model & $\%$ \\
& Pretension \\
\hline & $100 \%$ \\
$90 \%$ \\
$80 \%$ \\
Tipe JD2 & $70 \%$ \\
& $60 \%$ \\
$40 \%$ \\
$20 \%$ \\
$10 \%$ \\
\\
$100 \%$ \\
$90 \%$ \\
$80 \%$ \\
$70 \%$ \\
$60 \%$ \\
$40 \%$ \\
\\
\\
\end{tabular}

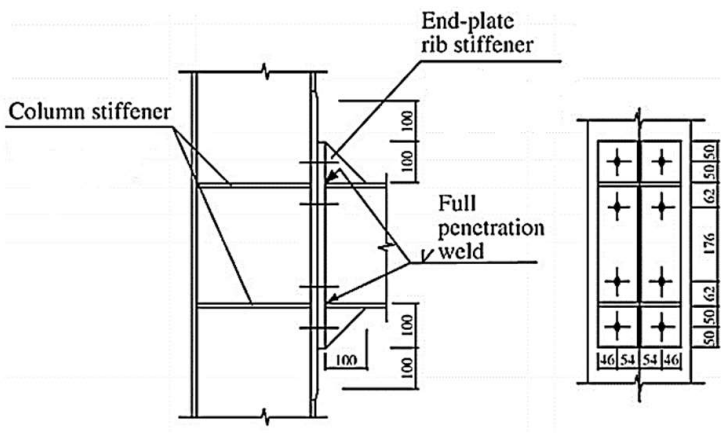

Gambar 4. Detail Sambungan untuk Spesimen JD2

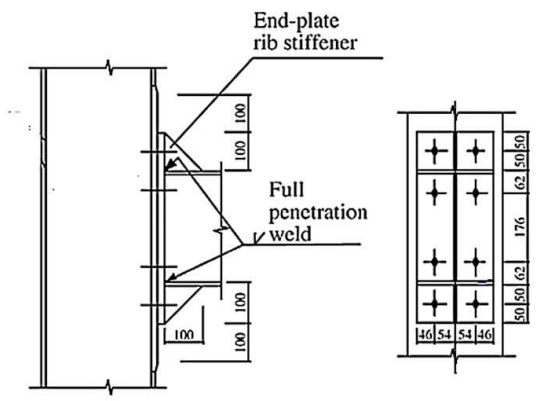

Gambar 5. Detail Sambungan untuk Spesimen JD4

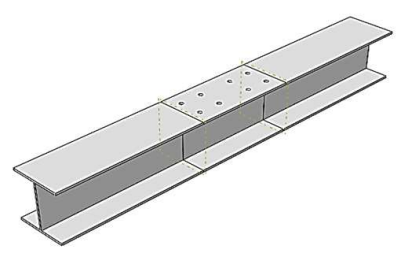

Gambar 6. Kolom Baja pada Modul Part

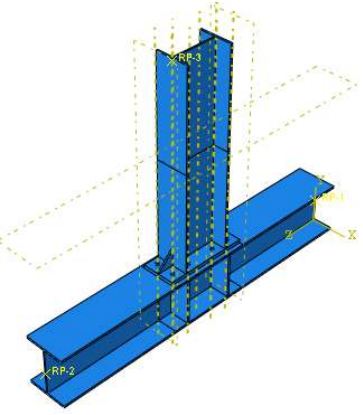

Gambar 7. Layout sambungan hasil assembly

Part yang telah dibuat, kemudian dirangkai menjadi satu kesatuan pada modul assembly. Pemodelan spesiman JD2 yang sudah dirangkai dapat dilihat pada Gambar 7. 
Kemudian masuk ke tahap modul step yang digunakan untuk menentukan langkah yang dilalui selama proses simulasi. Initial step sebagai kondisi gaya perletakan. Step-I dan step selanjutnya adalah pemberian beban displacement. Step dibuat sebanyak beban displacement yang akan diberikan.

Pada studi ini digunakan program ABAQUS untuk menganalisa model elemen hingga 3D. Pemodelan part steel dan bolts pada elemen sambungan menggunakan elemen solid hex yang dinamakan C3D8R pada ABAQUS. Ukuran meshing di daerah sambungan balok-kolom sebesar $50 \mathrm{~mm}$ sedangkan pada end-plate, column stiffener dan bagian lainnya sebsar $80 \mathrm{~mm}$. Mesh pemodelan ditunjukkan pada Gambar 8. Mesh berfungsi membagi geometri pemodelan menjadi node dan elemen.

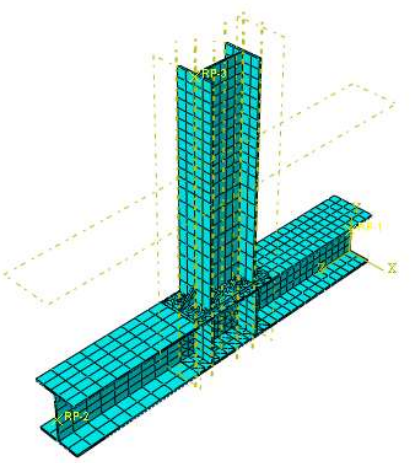

Gambar 8. Mesh pada Model Sambungan

\section{Boundary Condition}

Boundary condition yang diterapkan pada model ini adalah perletakan rol pada ujung kiri kolom dan pada ujung kanan kolom menggunakan perletakan sendi. Untuk bebannya, digunakan beban siklik yang diambil dari $S A C$ loading protocol, yaitu dengan diberi beban displacement diujung balok kantilever ke arah sumbu Z.

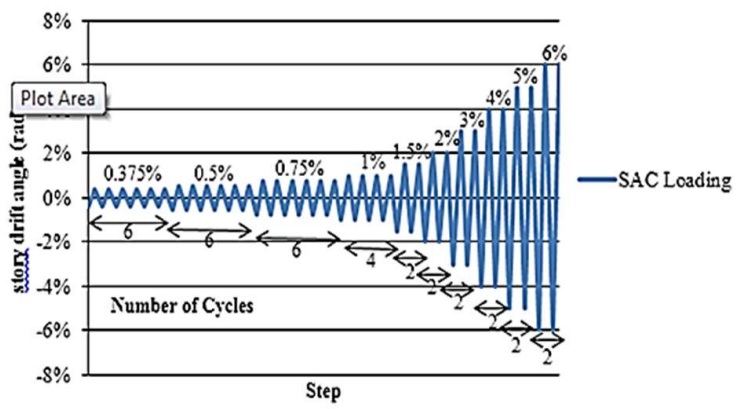

Gambar 9. Sistem Pembebanan

Adapun sistem pembebanan pada Gambar 9 adalah sistem pembebanan pada eksperimental yang juga sama digunakan pada pemodelan di ABAQUS. SAC loading pada pemodelan diinput dengan menggunakan modul amplitude dari penelitian Meng Wang et al. [11].

\section{Pembebanan}

Pembebanan yang terjadi pada pemodelan sesuai dengan eksperimen yang telah disajikan pada Gambar 10. Untuk pembebanan menggunakan 2 variasi beban, yaitu gaya aksial dan beban siklik. Pembebanan dimasukkan sesuai dengan variasi bebannya. Untuk gaya aksial yang berada di ujung kiri kolom sebesar $485 \mathrm{KN}$, sedangkan untuk beban siklik (P, $\Delta$ ) berada pada ujung balok. Pada program ABAQUS gaya aksial didefinisikan sebagai concentrated load di ujung kiri kolom dan beban siklik didefinisikan sebagai displacement/ rotation yang diletakkan di ujung kantilever balok. Gaya aksial diterapkan secara konstan. Sementara lateral displacement adalah beban yang berupa dorongan sampai jarak tertentu yang diterapkan bersama beban aksial yang bekerja secara konstan. Perletakan yang digunakan pada pemodelan ujung kolom dengan perletakan rol dan sendi.

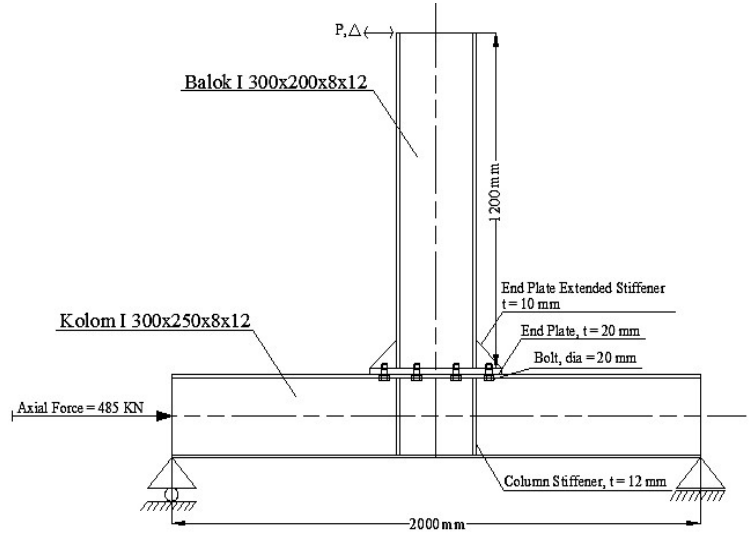

Gambar 10. Model Sambungan dan Pembebanan Pada Spesimen JD2

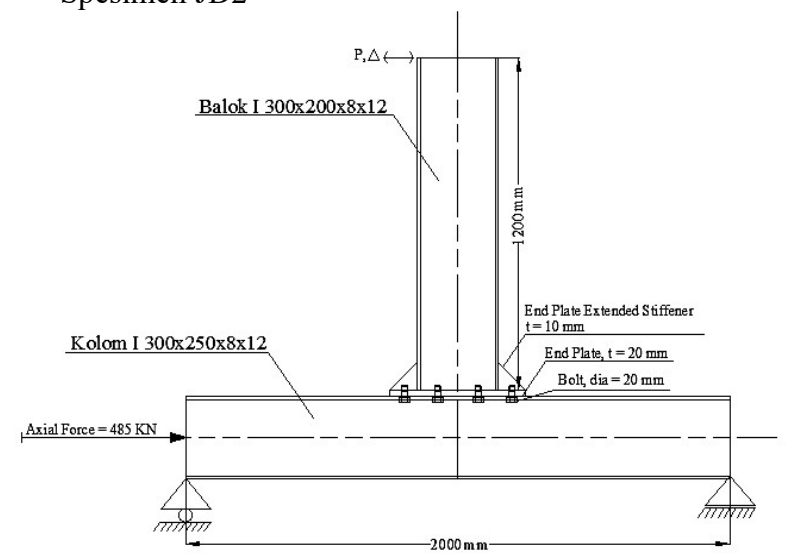

Gambar 11. Model Sambungan dan Pembebanan Pada Spesimen JD4 
Gambar 10 dan Gambar 11 menunjukkan model sambungan dengan geometri dan pembebanan yang nantinya akan dimodelkan pada program ABAQUS. Adapun Gambar 12 merupakan model sambungan yang di assembly dan diberi beban dan perletakan sesuai acuan eksperimental yang digunakan. Program ABAQUS memilih modul boundary condition XSYMM supaya mengunci arah X agar tidak dapat bergerak untuk perletakan rol di ujung kiri kolom sedangkan perletakan di ujung kanan kolom berupa pinned dimana dapat mengunci pemodelan sehingga tidak bergerak ke arah X, Y ataupun Z.

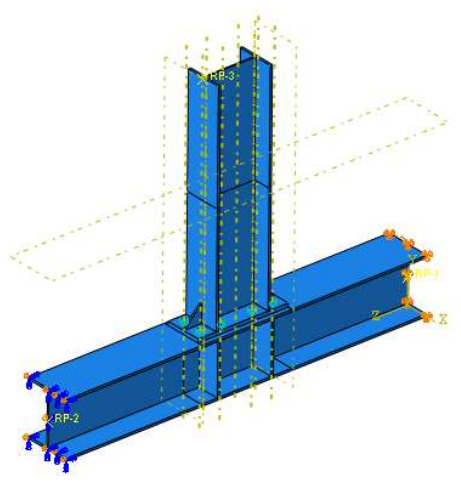

Gambar 12. Pembebanan pada Program ABAQUS

\section{Hasil dan Analisa}

Hasil pemodelan sambungan baja yang dianalisis dan pemodelan lanjutan adalah kurva force - displacement, momen-rotasi sambungan dengan beban siklik yang ditunjukkan pada kurva histerisis, distribusi tegangan $\mathrm{S}$ mises, nilai faktor daktilitas, envelope curve, kekakuan siklus $(\mathrm{Kc})$, disipasi energi dan perbandingan mode kegagalan dari spesimen yang dianalisis dengan mode spesimen eksperimental.

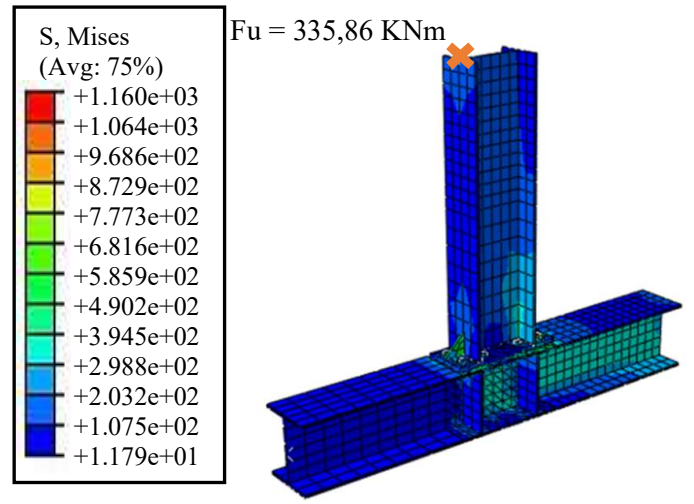

Gambar 13. Hasil S mises pada Model Sambungan Tipe JD2
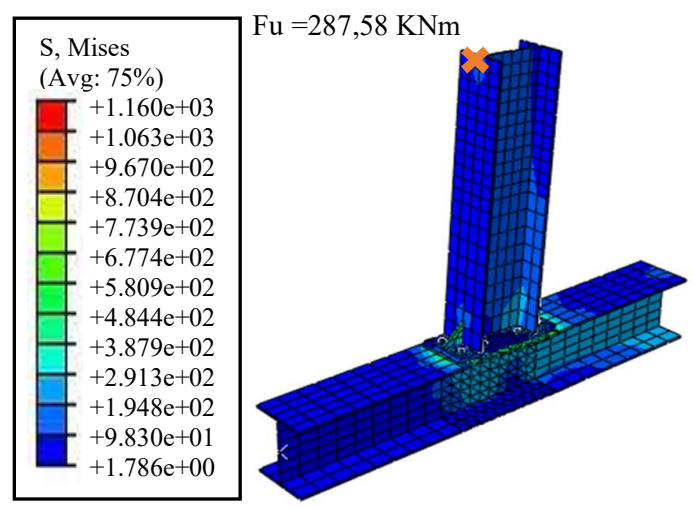

Gambar 14. Hasil S mises pada Model Sambungan Tipe JD4

Distribusi Tegangan akibat Beban Siklik Tipe JD2

Gambar 13 dan Gambar 14 menunjukkan distribusi tegangan yang terjadi akibat beban siklik pada model sambungan tipe JD2 dan tipe JD4.

\section{Hyteresis Loop (Momen-Rotasi)}

Dari analisa hyteresis loop, pemodelan JD2 dan JD4 telah mendekati hasil eksperimen yang ditinjau. Perbandingan analisa hyteresis loop ddan eksperimen pada pemodelan tipe JD2 dan JD4 dapat dilihat pada Gambar 15 dan Gambar 16.

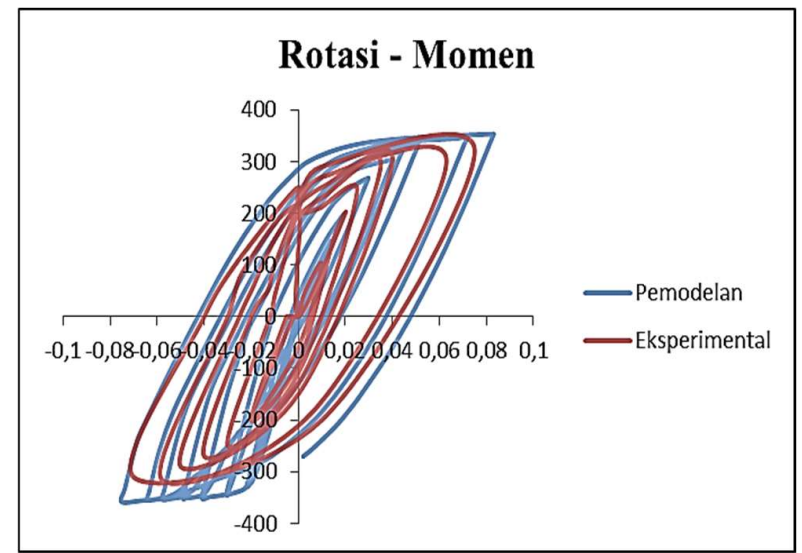

Gambar 15. Perbandingan Hyteresis Loop Eksperimen dengan Pemodelan Tipe JD2

Hasil dari analisis dengan finite element memberikan nilai momen dan rotasi mendekati dengan hasil eksperimen. Perbedaan hasil ini bisa disebabkan karena adanya ketidaksempurnaan geometri dan material yang digunakan pada pemodelan finite element. 


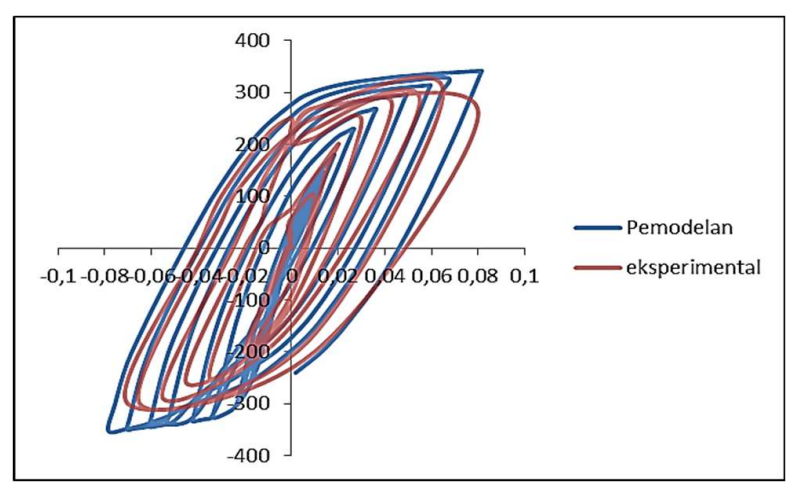

Gambar 16. Perbandingan Hyteresis Loop Eksperimen dengan Pemodelan Tipe JD4

\section{Daktilitas}

Faktor daktilitas struktur gedung $(\mu)$ adalah rasio antara simpangan ultimit dan simpangan pada saat terjadinya leleh pertama. Nilai defleksi failure untuk JD2 sebesar 95,923 mm sedangkan defleksi yield sebesar 32,011 mm dengan faktor daktilitas adalah 2,99. Untuk spesimen JD4 besar nilai defleksi failure adalah $85,363 \mathrm{~mm}$ dan defleksi yield sebesar 30,038 dengan faktor daktilitas sebesar 2,84.

Nilai tersebut menunjukkan bahwa faktor daktilitas spesimen JD2 sedikit lebih besar dibandingkan spesimen JD4 yaitu selisih 0,15 . Hal ini terjadi karena penurunan beban puncak pada spesimen JD2 dan JD4 terjadi pada saat drift ratio yang sedikit berbeda. Dengan mengacu pada peraturan syarat SRPMK untuk daktilitas adalah daktilitas penuh, sedangkan daktilitas pada spesimen yang telah dilakukan adalah daktilitas parsial, dengan syarat sebesar $1,5<\mu<5$.

\section{Envelope Curve}

Envelope curve terdiri dari beban puncak siklus pertama dari masing-masing siklus pembebanan lateral bolak - balik. Displacement arah positif menghasilkan envelope curve positif sedangkan displacement negatif menghasilkan envelope curve negatif. Kurva hasil perbandingan beban dan displacement dapat dilihat pada Gambar 17. Hasil tersebut menunjukkan bahwa spesimen JD2 mengalami pencapaian beban lateral maksimum tekan dan tarik serta penurunan beban tekan dan tarik pada level drift ratio yang berbeda, bila dibandingkan spesimen JD4.

Terlihat bahwa kapasitas beban lateral maksimal untuk spesimen JD2 sebesar 691,719 $\mathrm{KN}$ pada displacement 95,923 mm dan untuk spesimen JD4 sebesar 516,007 KN pada displacement $85,363 \mathrm{~mm}$. Ini menunjukkan bahwa kapasitas beban lateral spesimen JD2 lebih besar dari kapasitas beban spesimen JD4. Sehingga spesimen JD2 lebih mampu menahan beban lateral daripada spesimen JD4. Dari hasil tersebut terlihat bahwa spesimen JD2 lebih daktail bila dibandingkan dengan spesimen JD4.

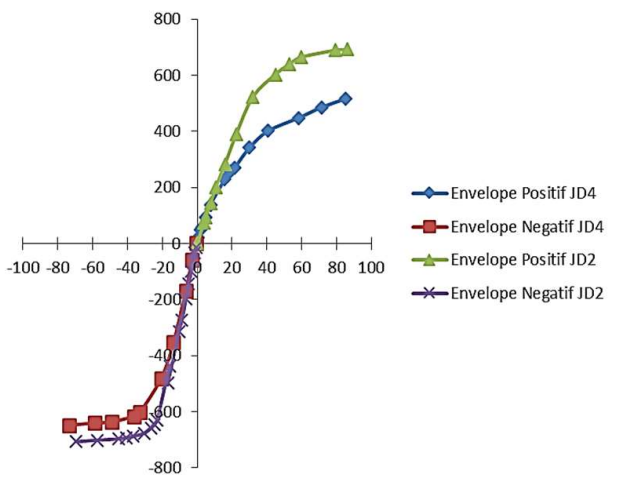

Gambar 17. Envelope Curve Pemodelan JD2 dan JD4

\section{Kekakuan Siklus (Kc)}

Kekakuan merupakan besarnya gaya yang mampu ditahan/diserap oleh struktur tiap satuan panjang. Kekakuan siklus pada pembebanan siklik secara umum akan mengalami penurunan pada setiap siklusnya, hal ini disebabkan karena pembebanan bolak-balik yang dilakukan menyebabkan efek kelelahan / fatique pada spesimen yang digunakan. Besarnya kekakuan siklus dapat dinyatakan dengan kekakuan rotasi. Dimana hasil kekakuan dapat dilihat pada Tabel 5.

\section{Disipasi Energi}

Energi disipasi menggambarkan kemampuan spesimen untuk mendisipasikan beban yang bekerja pada benda uji tersebut. Besarnya energi disipasi dihitung berdasarkan besarnya luasan kurva yang dibentuk dari satu siklus lengkap (positif dan negatif). Besarnya energi disipasi dihitung berdasarkan pendekatan numerik dengan cara menghitung luasan tiap pias pada siklus positif dan negatif oleh eksperimen Ambarita et al.[12]. Hasil rekapitulasi perhitungan dapat dilihat pada Tabel 6.

Mengacu pada hasil analisis yang telah dilakukan, rasio energi disipasi relatif pada spesimen JD2 dan JD4 lebih besar dari $1 / 8(0,125)$, sehingga masih memenuhi kriteria yang disyaratkan atau dengan kata lain struktur masih memiliki kemampuan untuk menjaga stabilitasnya sebelum runtuh.

Tabel 5. Verifikasi Nilai Kekakuan Rotasi JD2 dan JD4

\begin{tabular}{cccc}
\hline No & Spesimen & $\begin{array}{c}\text { Eksperimen } \\
k i \\
(\mathrm{KNm} / \mathrm{rad})\end{array}$ & $\begin{array}{c}\text { Pemodelan } \\
k i \\
(\mathrm{KNm} / \mathrm{rad})\end{array}$ \\
\hline 1 & JD2 & 68407 & 68733 \\
2 & JD4 & 35810 & 36175 \\
\hline
\end{tabular}


Tabel 6. Nilai Rasio Energi Disipasi

\begin{tabular}{ccc}
\hline Spesimen & $\begin{array}{c}\text { Luas Daerah } \\
\text { siklik } \\
\text { (KN.mm) }\end{array}$ & $\begin{array}{c}\text { Rasio Energi } \\
\text { disipasi relatif } \\
(\beta)\end{array}$ \\
\hline JD2 & 70712,75 & 0,51 \\
JD4 & 51662,30 & 0,45 \\
\hline
\end{tabular}

\section{Deformed Shape (Mode Kegagalan)}

Pengamatan pola kegagalan pada baut dan panel zone dimulai dari awal hingga akhir eksperimental yang dilakukan pada jurnal yang digunakan. Untuk spesimen sambungan baut JD2 sebesar $320,10 \mathrm{KNm}$ yang mengakibatkan kegagalan terjadi pada baut. Sedangkan pada spesimen JD4 terjadi kegagalan pada baut yang ditandai patah pada baut dan terjadi buckling pada panel zone kolom. Perbandingan kegagalan antara eksperimen dan pemodelan pada spesimen tipe JD2 dan JD4 dapat dilihat pada Gambar 18 dan Gambar 19.

Gambar 18 menunjukkan mode kegagalan terjadi pada baut. Adapun perbedaan selisih bentuk geometri akibat kegagalan pada baut dari eksperimental dan ABAQUS tidak terlalu signifikan. Dari spesimen JD2 ada dua baut di daerah luar extended plate yang mengalami patah pertama kali.

Gambar 19 menunjukkan mode kegagalan terjadi pada baut dan badan kolom. Ini diakibatkan karena kekakuan pada sayap kolom menurun secara signifikan karena tidak ada pengaku pada panel zone dan sayap kolom mengalami deformasi yang ditandai dengan perubahan rotasi pada sambungan tesebut.
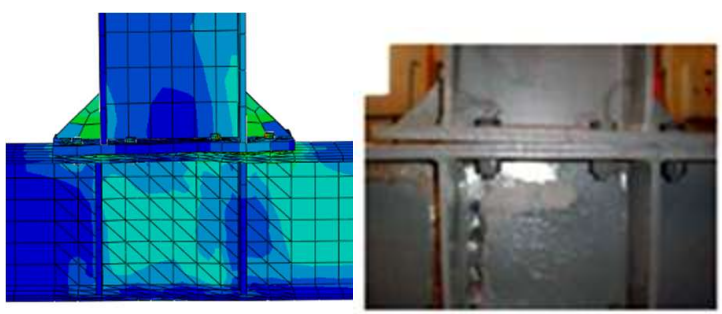

Gambar 18. Mode Kegagalan Eksperimental dan ABAQUS spesimen JD2

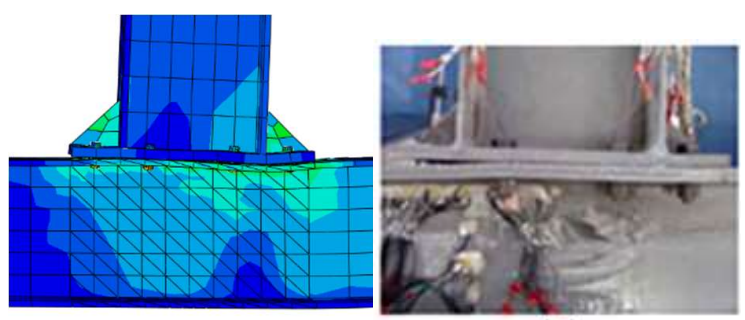

Gambar 19. Mode Kegagalan Eksperimental dan ABAQUS spesimen JD4

\section{Pemodelan Lanjutan}

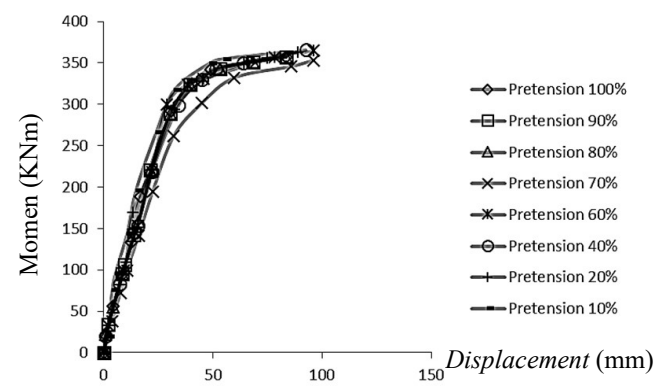

Gambar 20. Perbandingan \% Pratarik Baut Spesimen JD2

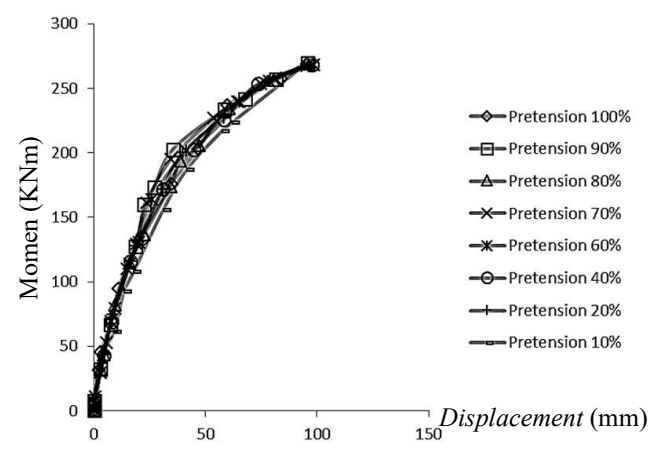

Gambar 21. Perbandingan \% Pratarik Baut Spesimen JD4

Dari Gambar 20 dan Gambar 21 dapat dilihat perbandingan perubahan momen dan displacement antara spesimen tipe JD2 dan tipe JD4. Dari hasil tersebut dapat diambil kesimpulan bahwa nilai displacementdengan menggunakan pretension (pratarik) yang lebih rendah dari $70 \%$ yang disyaratkan akan menimbulkan displacement yang lebih besar dari pada menggunakan pretension (pratarik) yang lebih tinggi. Sedangkan untuk nilai kuat tarik sambungan baut atau gaya menyebabkan kegagalan baut untuk tipe JD2 dengan nilai antara $350-400 \mathrm{KNm}$ dan untuk tipe JD4 antara nilai $250-300 \mathrm{KNm}$.

\section{Kesimpulan}

Pemodelan yang dianalisis didapat nilai momen-rotasi pada eksperimental dan pemodelan pada setiap spesimen. Untuk spesimen JD2 pada eksperimental momen sebesar $320,10 \mathrm{KNm}$ sedangkan pemodelan $335,86 \mathrm{KNm}$ dengan selisih sebesar $15,76 \mathrm{KNm}$. Untuk nilai rotasi pada spesimen JD2 pada eksperimental sebesar 0,040 rad sedangkan pemodelan 0,042 rad dengan selisih sebesar 0,002 rad. Untuk spesimen JD4 nilai momen untuk eksperimental dan pemodelan selisih sebesar $1,82 \mathrm{KNm}$ dan rotasi $0,003 \mathrm{rad}$. Sambungan pada pemodelan yang dilakukan adalah sambungan friksi dengan menggunakan baut mutu tinggi (HTB). Sambungan friksi yang menggunakan baut mutu tinggi yang dikencangkan akan menimbulkan tarikan baut 
minimum. Sambungan direncanakan dengan mekanisme slip kritis dan mekanisme tumpu yang bekerja pada baut. Pemberian beban awal sekitar 70\% - 80\% dari kekuatan tarikan maksimumnya.

\section{Daftar Pustaka}

[1] L. Handayani, "Peningkatan aktivitas gempa bumi di Indonesia tahun 1973 - 2009," J. Lingkung. dan Bencana Geol., Vol. 1, no. 2, pp. 71-78, 2010.

[2] M. Ghassemieh, M. Jalalpour, and A. A. Gholampour, "Numerical Evaluation of the Extended Endplate Moment Connection Subjected to Cyclic Loading," Curr. Adv. Civ. Eng., Vol. 2, no. 1, pp. 35-43, 2014.

[3] B. Tayu et al., "Perilaku Sambungan Baut Flush EndPlate Balok," Vol. 5, no. 5, 2017.

[4] AISC, "Specification for Structural Steel Buildings," Ansi/Aisc 360-16, 2016.

[5] A. Haghollahi and R. Jannesar, "Cyclic Behavior of Bolted Extended End-Plate Moment Connections with Different Sizes of End Plate and Bolt Stiffened by a Rib Plate," Civ. Eng. J., vol. 4, no. 1, p. 200 , 2018.

[6] A. Ghobarah, A. Osman, and R. M. Korol, "Behaviour of extended end-plate connections under cyclic loading," Eng. Struct., Vol. 12, no. 1, pp. 15-27, 1990.

[7] S. El-Khoriby, M. A. Sakr, T. M. Khalifa, and M. M. Eladly, "Modelling and behaviour of beam-to-column connections under axial force and cyclic bending," $J$. Constr. Steel Res., Vol. 129, pp. 171-184, 2017.

[8] M. Valerio, "Response of Flush End' Plate Joints Under Combined Actions," Engineering of Civil and Mechanical System, 2012, University of Trento New Jersey.

[9] G. Shi, Y. Shi, and Y. Wang, "Behaviour of end-plate moment connections under earthquake loading," J. of Eng. Struct., Vol. 29, no. 5, pp. 703-716, 2007.

[10] Badan Standardisasi Nasional, "Spesifikasi Untuk Bangunan Gedung Baja Struktural. SNI 03-17292015," 2015.

[11] M. Wang, Y. Shi, Y. Wang, and G. Shi, "Numerical study on seismic behaviors of steel frame end-plate connections," J. Constr. Steel Res., Vol. 90, pp. 140$152,2013$.

[12] J. Ambarita et al., "Pendekatan Model Hysteristic Steel Damper Berdasarkan Hasil Eksperimental," Jurnal Teknik Sipil USU, Vol. 3, no. 1, pp. 1-11, 2014. 